\title{
The molecular background to hypophosphataemic rickets
}

Bone mineral loss disorders are major, worldwide health concerns, and can be familial, idiopathic, oncogenic, dietary, or hormonal. The mechanisms controlling bone integrity are complex. Extensive research has been directed towards the characterisation of the key factors involved in bone mineral regulation and two specific bone diseases, $\mathrm{X}$-linked hypophosphataemic rickets (HYP) and oncogenic hypophosphataemic osteomalacia (OHO). The primary defect in HYP is a defective zinc metalloendopeptidase (PHEX), ${ }^{1-4}$ and a new candidate glycoprotein (MEPE) has been proposed as the phosphaturic factor released by OHO tumours. ${ }^{56}$ Both diseases cause severe changes in bone morphology and have an overlapping pathophysiology. This review will discuss the recent molecular advances in our understanding of the role of the kidney and other organs in bone mineral homeostasis, with emphasis on X-linked hypophosphataemic rickets and tumour osteomalacia.

\section{Clinical features of HYP and tumour osteomalacia} Classic, vitamin D resistant HYP(MIM \#307800), is characterised by:

- Hypophosphataemia

- Renal phosphate leak as expressed as a lowered transfer maximum of phosphate per unit volume of glomerular filtrate (TMPO4/GFR)

- Inappropriate vitamin D metabolism in the presence of low serum phosphate (low to normal serum 1,25 dihydroxy vitamin D3; calcitriol)

- High alkaline phosphatase

- Skeletal defects. ${ }^{7}$

OHO shares many clinical, biochemical, and physiological features with HYP. ${ }^{9}$ The tumours are mainly of mesenchymal origin, although a number of different tumour types have been reported. ${ }^{10}{ }^{11}$ Evidence indicates that changes in renal phosphate handling, vitamin D metabolism, and skeletal mineralisation are caused by factor(s) secreted by OHO tumours. ${ }^{8-10} 12-19$ The resection of OHO tumours results in the disappearance of disease symptoms and bone healing and is a key observation that supports this. $^{81220}$

\section{Cloning of the rickets gene}

The rickets gene PHEX (phosphate regulating gene with endopeptidase activity on the $\mathrm{X}$ chromosome), ${ }^{12}$ is a zinc metalloendopeptidase with close homologies to an M13 family of type II glycoproteins. Neprilysin (NEP) is a prototypic member of the M13 family. Human PHEX and its cDNA have been characterised fully, ${ }^{134}$ and extensive mutation analysis has confirmed that the defect in HYP can be attributed to primary mutations in the PHEX gene. ${ }^{31-24}$ Two murine homologues (HYP and Gy), for $\mathrm{X}$-linked rickets have been characterised, ${ }^{25}{ }^{26}$ and deletions in the murine Phex gene were discovered at the $3^{\prime}$ and 5' ends respectively. ${ }^{27}$ Mutation analysis combined with molecular modelling and comparison of data for NEP and thermolysin has enabled a model for the catalytic site of human PHEX to be proposed. ${ }^{3811} 12$

\section{PHEX/Phex tissue expression}

A defined pattern of PHEX/Phex expression has emerged after screening a large range of tissue types. Mouse bone, ${ }^{28}{ }^{29}$ mouse teeth, ${ }^{30}$ human fetal bone, ${ }^{28} 29$ human lung, ${ }^{28}{ }^{31}$ and adult human ovary ${ }^{31}$ all express PHEX/Phex mRNA. The highest relative levels of expression were measured in bones ${ }^{28}$ and teeth. ${ }^{30}$ No PHEX expression has yet been recorded in kidney, ${ }^{28}{ }^{30-32}$ while PHEX expression occurs in $\mathrm{OHO}$ tumours. ${ }^{29}$ Recombinant expression of PHEX and assessment of its subcellular localisation supports the molecular predictions that PHEX is a type II integral membrane glycoprotein. ${ }^{29}$

\section{Physiological and molecular changes in HYP and tumour osteomalacia}

Extensive research has been carried out on murine models of rickets, and a number of reviews have described this work. ${ }^{811} 12$ 33-36 Several distinct molecular processes are defective and include:

- Renal phosphate handling (renal $\mathrm{Na}$ dependent phosphate co-transport)

- Aspects of vitamin D metabolism

- Phosphorylation of specific extracellular bone matrix proteins (EBMPs)

- Expression of specific EBMPs

- Protein kinase $\mathrm{C}$ and skeletal casein kinase II expression

- Osteoblast bone cell function and skeletal mineralisation.

All the abnormal changes described are now known to be due to a primary defect in the PHEX gene. ${ }^{34} 2123242728$ Tumour osteomalacia has very similar clinical and biochemical features to HYP, and it is likely that the tumour may secrete a key factor regulated or processed by PHEX. The following section will review the above areas in relation to HYP, OHO and normal molecular physiology.

RENAL PHOSPHATE TRANSPORT

Inorganic phosphate $\left(\mathrm{PO}_{4}\right)$ is reabsorbed from the glomerular filtrate by a number of distinct $\mathrm{Na}^{+}$dependent phosphate co-transporters (NaPI). Three classes of NaPI transporters have been characterised:

- NPT1 (type 1),

- NPT2 (type 2)

- Viral cellular receptors Glrv 1, and RAM $1 . .^{37}$

Various isoforms of these transporters have also been discovered, ${ }^{39}$ and a separate gene has been cloned that has close homologies to renal NPT2. The new transporter is classified as type $2 \mathrm{~b}$ (NPT2b) and the human gene (NaPi $3 \mathrm{~b}$ ) is expressed in intestines and lung. ${ }^{40}{ }^{42}$ Also, human NPT2 (NaPi 3) contains a vitamin D response element and is thus regulated by calcitriol ${ }^{42}$ at the nuclear level.

In familial X-linked rickets, early renal phosphate transport studies were carried out on the HYP mouse. ${ }^{35}$ Renal defects were found in a NaPI transporter localised to the brush border membranes of the proximal convoluted tubules, and this was later confirmed to be due to down regulation of mRNA and protein of the NPT2 class of phosphate transporters. ${ }^{34} 364344$ Mouse gene knockout experiments have shown that NPT2 has a major role in regulating phosphate homeostasis and skeletal development, but does not produce an X-linked rickets phenotype. ${ }^{45}$ More recently, downregulation of murine NPT1 transporters in HYP has also been observed, although the decrease was $20 \%$ compared with $50 \%$ for NPT2. ${ }^{44}$ The phosphate defect in rickets mice persists after parathyroidectomy and predominantly involves a high affinity, low capacity $\mathrm{Na}^{+}$phosphate co-transport system. ${ }^{8345}$ There is considerable and impressive experimental evidence that supports the role of a circulating factor regulating phosphate in the kidney. These data have been extensively reviewed. ${ }^{8113435}$ 
VITAMIN D METABOLISM

In HYP and $\mathrm{OHO}$, low serum phosphate does not initiate an increase in calcitriol and the levels are either inappropriately low to normal (HYP), or severely reduced (OHO). Also, in complete contrast to normal mice, HYP mice fed low phosphate diets have decreased 1, 25-(OH2) D3 levels and HYP mice on phosphate supplemented diets have increased concentrations of 1,25 (OH)2 D3 in serum. The acute, maladaptive regulatory response of at least two key enzymes, renal $1 \alpha$ hydroxylase and the 24 hydroxylase (upregulated), are responsible for the abnormal modulation of serum calcitriol. ${ }^{46} 47$

PHEX expression is downregulated by calcitriol, ${ }^{2}{ }^{48}$ and it is of interest to speculate how this might also contribute to aberrant vitamin D metabolism in HYP. It is possible that PHEX is required to process a molecule that directly or indirectly regulates aspects of vitamin D metabolism, and calcitriol modulates this by feedback suppression of PHEX synthesis. Loss of PHEX activity in HYP might therefore interfere with this regulatory mechanism, resulting in inappropriate $1 \alpha$ hydroxylase and 24 hydroxylase activity. Also, Phex expression increases as osteoblasts mature and appears to be associated with matrix mineralisation..$^{35} 48$ In contrast, calcitriol inhibits bone mineralisation and the interconnected expression of both Phex and calcitriol may therefore be required for appropriate bone mineral homeostasis.

BONE

Profound changes in bone morphology occur in both HYP and $\mathrm{OHO} .{ }^{78}$ In HYP mice, intrinsic osteoblast defects are apparent that are not associated directly with the hypophosphataemia, renal phosphate leak, or altered vitamin D status. Intramuscular transplantation of normal and HYP mice osteoblasts or periostea have provided experimental evidence for osteoblast defects. ${ }^{49-51}$ Histomorphometric analysis of the transplanted cells demonstrate that HYP osteoblast mineralisation function is intrinsically abnormal. Major differences in Hyp osteoblast cultures in response to alkaline phosphatase and calcitriol mediated proliferation regulated by phosphate also suggests that an intrinsic osteoblast factor plays a role. ${ }^{52}$ Other skeletal related defects have been reported and include increased osteoblast gluconeogenesis associated with decreased intracellular $\mathrm{pH}^{53}$ reduced casein kinase II activity and decreased osteopontin (OPN) phosphorylation. ${ }^{54}$

\section{MODELS}

Key features concerning phosphate/calcium renal bone homeostasis are beginning to emerge and models can now be proposed that take into account the new findings. PHEX/Phex may cleave and process a factor or factors that are essential for phosphate handling, osteoblast/ odontoblast function, mineralisation, and growth. It is also possible that $\mathrm{PHEX} / \mathrm{Phex}$ as a homodimer and/or heterodimer plays a pivotal role in the processing of an important renal phosphate regulating factor that directly or indirectly impacts on bone mineralisation/remodelling. This factor is likely processed sequentially via specific proteolytic cleavage to generate a number of bioactive peptides that impact on phosphate regulation and/or bone mineralisation. Other modes of post-translational cleavage of these peptides cannot be excluded and phosphorylation may also play a role. The under-phosphorylation of osteopontin due to defective skeletal casein kinase II (CK-II) in $\mathrm{Hyp}^{54}$ and the discovery of cell surface CK-II ectokinase activity in osteoblasts $^{55}$ underlines the importance of protein phosphorylation. The fact that Phex expression is suppressed by calcitriol suggests that one or more of these peptides may well impact on the regulation of vitamin $\mathrm{D}$ metabolism by suppressing or activating key catabolic or anabolic enzymes such as 1- $\alpha$-hydroxylase or 24-hydroxylase. This in turn may affect osteoblast and osteoclast function. Elegant experiments demonstrating the role of an intrinsic osteoblast defect in Hyp mice, ${ }^{49} 50567$ and the finding that Phex expression is predominant in osteoblasts/bone/teeth, ${ }^{28}$ 30-32 suggests that some of the processed peptides may have an autocrine effect on osteoblast/odontoblast function as well as a paracrine effect on renal phosphate handling.

Of direct relevance to a putative phosphaturic factor is the recent cloning from $\mathrm{OHO}$ tumours of an RGD containing glycoprotein MEPE (matrix extracellular-phosphoglycoprotein). ${ }^{56}$ MEPE has close similarities to bone and dentin extracellular matrix proteins (Dentin-matrix protein-I, osteopontin, dentin sialophosphoprotein, bone sialo protein-II). This protein is highly expressed in OHO tumours but not in nonphosphaturic tumours and is also highly expressed in bone marrow and brain. Although yet to be confirmed unequivocally, MEPE is a good candidate for the uncharacterised phosphaturic factor (phosphatonin), that has been proposed to be processed directly or indirectly by PHEX .

An increased understanding of the mechanisms controlling bone-renal biochemistry and physiology is prerequisite to improving the clinical management of bone loss disorders (inherited or acquired). Recent advances have provided researchers with new insights that will ultimately contribute to the achievement of this goal.

The author would like to acknowledge and thank the Medical Research Council of the United Kingdom for their support in the form of an MRC Senior Fellowship.

P S N ROWE

Roval Free and University College Medical School, Department of Biochemistry and Molecular Biology, Centre for Molecular Osteo-Renal Research, Rowland Hill Street, Hampstead, London NW3 2PF, UK

Correspondence to: Dr Rowe

email: p.rowe@rfc.ucl.ac.uk

1 HYP consortium, Francis F, Hennig S, et al. A gene (PEX) with homologies to endopeptidases is mutated in patients with X-linked hypophosphatemic rickets. The HYP Consortium. Nat Genet 1995;11:130-6.

2 Rowe PSN, Goulding JN, Francis F, et al. The gene for X-linked hypophosphataemic rickets maps to a $200-300 \mathrm{~kb}$ region in Xp22.1, and is located on a single YAC containing a putative vitamin D response element (VDRE). Hum Genet 1996;97:345-52.

3 Rowe PS, Oudet CL, Francis F, et al. Distribution of mutations in the PEX gene in families with X-linked hypophosphataemic rickets (HYP). Hum gene in families with X-lin

4 Francis F, Strom TM, Hennig S, et al. Genomic organization of the human PEX gene mutated in X-linked dominant hypophosphatemic rickets. Genome Res 1997;7:573-85.

5 Rowe PS, de Zoysa P, Dong R, et al. MEPE, a new gene expressed in bonemarrow and tumours causing osteomalacia. Genomics 2000;67:54-68.

6 Rowe PS, Ong AC, Cockerill FJ, Goulding JN, Hewison M. Candidate 56 and $58 \mathrm{kDa}$ protein(s) responsible for mediating the renal defects in oncogenic hypophosphatemic osteomalacia. Bone 1996;18:159-69.

7 Carpenter TO. New perspectives on the biology and treatment of X-linked hypophosphatemic rickets. Pediatr Clin North Am 1997;44:443-66.

8 Rowe PS. The role of the PHEX gene (PEX) in families with X-linked hypophosphataemic rickets. Curr Opin Nephrol Hypertens 1998;7:367-76.

9 Nelson AE, Robinson BG, Mason RS. Oncogenic osteomalacia: is there a new phosphate regulating hormone? Clin Endocrinol (Oxf) 1997;47:63542 .

10 Drezner MK. Tumour-associated rickets and osteomalacia. In: Favus MJ, Christakos S, Goldring SR, Holick MF eds. Primer on the metabolic bone diseases and disorders of mineral metabolism. An official publication of the American Society for Bone and Mineral Research. Kelseyville, CA: LippinAmerican Society for Bone and Mineral

11 Rowe PS. The PEX gene: its role in X-linked rickets, osteomalacia, and bone mineral metabolism. Exp Nephrol 1997;5:355-63.

12 Rowe PSN. X-linked rickets and tumour osteomalacia: PHEX and the missing link. Clinical and Experimental Nephrology 1998;2:183-93.

13 Nitzan DW, Horowitz AT, Darmon D, et al. Oncogenous osteomalacia: a case study. Bone Miner 1989;6:191-7.

14 Aschinberg LC, Solomon LM, Zeis PM, Justice P, Rosenthal IM. Vitamin D-resistant rickets associated with epidermal nevus syndrome: demonstration of a phosphaturic substance in the dermal lesions. 7 Pediatr 1977;91:56-60.

15 Chalew SA, Lovchik JC, Brown CM, Sun CC. Hypophosphatemia induced in mice by transplantation of a tumor-derived cell line from a patient with oncogenic rickets. F Pediatr Endocrinol Metab 1996;9:593-7.

16 Miyauchi A, Fukase M, Tsutsumi M, Fujita T. Hemangiopericytomainduced osteomalacia: tumour transplantation in nude mice causes induced osteomalacia: tumour transplantation in nude mice causes
hypophosphatemia and tumor extracts inhibit renal 25 -hydroxyvitamin D 1-hydroxylase activity. $\mathcal{F}$ Clin Endocrinol Metab 1988;67:46-53. 
17 Cai Q, Hodgson SF, Kao PC, et al. Brief report: inhibition of renal phosphate transport by a tumor product in a patient with oncogenic osteophosphate transport by a tumor product in
malacia. $N$ Engl $\mathcal{F}$ Med 1994;330:1645-9.

18 Kumar R, Haugen JD, Wieben ED, Londowski JM, Cai Q. Inhibitors of renal epithelial phosphate transport in tumor-induced osteomalacia and uremia. Proc Assoc Am Physicians 1995;107:296-305.

19 Nelson AE, Namkung HJ, Patava J, et al. Characteristics of tumor cell bioactivity in oncogenic osteomalacia. Mol Cell Endocrinol 1996;124:17-23.

20 Drezner MK. The role of abnormal vitamin D metabolism in X-linked hypophosphatemic rickets and osteomalacia. Adv Exp Med Biol 1984;178: 399-404.

21 Holm IA, Huang X, Kunkel LM. Mutational analysis of the PEX gene in patients with X-linked hypophosphatemic rickets. Am f Hum Genet 1997;60:790-7.

22 Filisetti D, Osterman G, von Bredow M, et al. Non-random distribution of mutations in the PHEX gene, and under-detected missense mutations at non-conserved residues. Eur f Hum Genet 1999;7:615-19.

23 Econs MJ, Friedman NE, Rowe PN, et al. A PEX gene mutation is responsible for adult onset vitamin D resistant hypophosphatemic osteomalacia: Evidence that the disorder is not a distinct entity from X-linked hypophosEvidence that the disorder is not a distinct entity from X-linked hypoph

24 Dixon PH, Christie PT, Wooding C, et al. Mutational analysis of PHEX gene in X-linked hypophosphatemia. F Clin Endocrinol Metab 1998;83:

25 Eicher EM, Southard JL, Scriver CR, Glorieux FH. Hypophosphatemia: mouse model for human familial hypophosphatemic (vitamin D-resistant) rickets. Proc Natl Acad Sci US A 1976;73:4667-71

26 Lyon MF, Scriver CR, Baker LR, Tenenhouse HS, Kronick J, Mandla S. The Gy mutation: another cause of X-linked hypophosphatemia in mouse. Proc Natl Acad Sci U S A 1986;83:4899-903.

27 Strom TM, Francis F, Lorenz B, et al. Pex gene deletions in Gy and Hyp mice provide mouse models for X-linked hypophosphatemia. Hum Mol Genet 1997;6:165-71.

28 Beck L, Soumounou Y, Martel J, et al. Pex/PEX tissue distribution and evidence for a deletion in the 3' region of the Pex gene in X-linked hypophosphatemic mice. 7 Clin Invest 1997;99:1200-9.

29 Lipman ML, Panda D, Bennett HP, et al. Cloning of human PEX cDNA. Expression, subcellular localization, and endopeptidase activity. $\mathcal{F}$ Biol Chem 1998;273:13729-37.

30 Ruchon AF, Marcinkiewicz M, Siegfried G, et al. Pex mRNA is localized in developing mouse osteoblasts and odontoblasts. F Histochem Cytochem 1998;46:459-68.

31 Grieff M, Mumm S, Waeltz P, et al. Expression and cloning of the human $\mathrm{X}$-linked hypophosphatemia gene cDNA. Biochem Biophys Res Commun 1997;231:635-9.

32 Du L, Desbarats M, Viel J, Glorieux FH, Cawthorn C, Ecarot B. cDNA cloning of the murine Pex gene implicated in X-linked hypophosphatemia and evidence for expression in bone. Genomics 1996;36:22-8.

33 Rowe PS. Molecular biology of hypophosphataemic rickets and oncogenic osteomalacia. Hum Genet 1994;94:457-67.

34 Tenenhouse HS. Cellular and molecular mechanisms of renal phosphate transport. F Bone Miner Res 1997;12:159-64.

35 Tenenhouse HS. X-linked hypophosphataemia: a homologous disorder in humans and mice. Nephrol Dial Transplant 1999;14:333-41.

36 Tenenhouse HS, Werner A, Biber J, et al. Renal Na(+)-phosphate cotransport in murine X-linked hypophosphatemic rickets. F Clin Invest 1994;93:671-6.

37 Takeda E, Taketani Y, Morita K, Miyamoto K. Sodium-dependent phosphate co-transporters. Int f Biochem Cell Biol 1999;31:377-81.

38 Tenenhouse HS. Recent advances in epithelial sodium-coupled phosphate Tenenhouse HS. Recent advances in epithelial sodium-

39 Tatsumi S, Miyamoto K, Kouda T, et al. Identification of three isoforms for the Na+-dependent phosphate cotransporter $(\mathrm{NaPi}-2)$ in rat kidney. $\mathcal{F}$ Biol Chem 1998;273:28568-75.
40 Feild JA, Zhang L, Brun KA, Brooks DP, Edwards RM. Cloning and functional characterization of a sodium-dependent phosphate transporter expressed in human lung and small intestine. Biochem Biophys Res Commun 1999;258:578-82.

41 Hilfiker H, Hattenhauer O, Traebert M, Forster I, Murer H, Biber J. Characterization of a murine type II sodium-phosphate cotransporter expressed in mammalian small intestine. Proc Natl Acad Sci U S A 1998;95:14564-9.

42 Taketani Y, Segawa H, Chikamori M, et al. Regulation of type II renal Na+dependent inorganic phosphate transporters by 1,25-dihydroxyvitamin D3. Identification of a vitamin D- responsive element in the human NAPi-3 gene. I Biol Chem 1998;273:14575-81.

43 Tenenhouse HS, Beck L. Renal $\mathrm{Na}(+)$-phosphate cotransporter gene expression in X-linked Hyp and Gy mice. Kidney Int 1996;49:1027-32.

44 Tenenhouse HS, Roy S, Martel J, Gauthier C. Differential expression, abundance, and regulation of $\mathrm{Na}+$-phosphate cotransporter genes in murine kidney. Am f Physiol 1998;275:F527-34

45 Beck L, Karaplis AC, Amizuka N, Hewson AS, Ozawa H, Tenenhouse HS. Targeted inactivation of Npt2 in mice leads to severe renal phosphate wasting, hypercalciuria, and skeletal abnormalities. Proc Natl Acad Sci U S A 1998;95:5372-7.

46 Yamaoka K, Seino Y, Satomura K, Tanaka Y, Yabuuchi H, Haussler MR. Abnormal relationship between serum phosphate concentration and renal 25-hydroxycholecalciferol-1-alpha-hydroxylase activity in X-linked hypophosphatemic mice. Miner Electrolyte Metab 1986;12:194-8.

47 Roy S, Tenenhouse HS. Transcriptional regulation and renal localization of 1,25-dihydroxyvitamin D3-24-hydroxylase gene expression: effects of the Hyp mutation and 1,25-dihydroxyvitamin D3. Endocrinology 1996;137: 2938-46.

48 Ecarot B, Desbarats M. 1,25- $(\mathrm{OH}) 2 \mathrm{D} 3$ down-regulates expression of Phex, a marker of the mature osteoblast. Endocrinology 1999;140:1192-9.

49 Ecarot B, Glorieux FH, Desbarats M, Travers R, Labelle L. Defective bone formation by Hyp mouse bone cells transplanted into normal mice: evidence in favor of an intrinsic osteoblast defect. F Bone Miner Res 1992;7: 215-20.

50 Ecarot B, Glorieux FH, Desbarats M, Travers R, Labelle L. Effect of 1,25dihydroxyvitamin D3 treatment on bone formation by transplanted cells from normal and X-linked hypophosphatemic mice. $\mathcal{F}$ Bone Miner Res 1995;10:424-31.

51 Tanaka H, Seino Y, Shima M, et al. Effect of phosphorus supplementation on bone formation induced by osteosarcoma-derived bone-inducing substance in X-linked hypophosphatemic mice. Bone Miner 1988;4:23746.

52 Yamamoto T, Ecarot B, Glorieux FH. Abnormal response of osteoblasts from Hyp mice to 1,25-dihydroxyvitamin D3. Bone 1992;13:209-15.

53 Rifas L, Gupta A, Hruska KA, Avioli LV. Altered osteoblast gluconeogenesis in $\mathrm{X}$-linked hypophosphatemic mice is associated with a depressed intracellular $\mathrm{pH}$. Calcif Tissue Int 1995;57:60-3.

54 Rifas L, Cheng S, Halstead LR, Gupta A, Hruska KA, Avioli LV. Skeletal casein kinase activity defect in the HYP mouse. Calcif Tissue Int 1997;61:256-9.

55 Zhu X, Luo C, Ferrier JM, Sodek J. Evidence of ectokinase-mediated phosphorylation of osteopontin and bone sialoprotein by osteoblasts during bone formation in vitro. Biochem f 1997;323:637-43.

56 Yoshikawa H, Masuhara K, Takaoka K, Ono K, Tanaka H, Seino Y. Abnormal bone formation induced by implantation of osteosarcoma-derived bone-inducing substance in the X-linked hypophosphatemic mouse. Bone 1985;6:235-9.

57 Ecarot-Charrier B, Glorieux FH, Travers R, Desbarats M, Bouchard F, Hinek A. Defective bone formation by transplanted Hyp mouse bone cells into normal mice. Endocrinology 1988;123:768-73. 